\title{
RESEARCH ON NORMATIVE EXPRESSIONS OF GEOMATICS ELEMENTS FROM THE PERSPECTIVE OF QUALITY INSPECTION
}

\author{
LUO Fujun ${ }^{1}$, ZHANG Pengcheng $^{1, *}$, MA Xu${ }^{1}$, BAI Jin ${ }^{1}$ \\ ${ }^{1}$ National Quality Inspection and Testing Center for Surveying and Mapping Products, 28 Lianhuachi West Road, Haidian District, \\ Beijing-1254020931@qq.com
}

KEY WORDS: Geomatics Elements, Normative Expressions, Quality Inspection, Natural Resources, Co-construction and sharing, Surveying and Mapping

\begin{abstract}
:
At present, social and economic development has entered a new era. The establishment of the Ministry of Natural Resources has strengthened the functions of the natural resources department to provide the government and the public with standard, accurate, authoritative and reliable geomatics data recognized by various sectors, and has also put forward higher requirements for the quality of geomatics data.

The definition of some elements in the geomatics standards is ambiguous or even contradictory, which interferes with the work level of production personnel, affects the ability of quality inspectors to determine quality problems accurately and efficiently, reduces the consistency of geographic information data, and limits the promotion and use of the products.

The fundamental way to solve this problem is to unify the understanding of products, quality inspection and application, to comprehensively consider different scales, different terrain types and different types of results, and to define geomatics elements precisely, clearly and uniformly so that practitioners in different links can reach a consensus and have no ambiguity in the understanding of the elements. This work is not only conducive to reducing friction among products, quality inspection and application, but also the basis for realizing the co-construction and sharing of geographic information data among various sectors.
\end{abstract}

\section{GENERAL INSTRUCTIONS}

Terminology is a collection of titles used to represent concepts in a specific subject area. It is also called a noun or a scientific noun in China. Terminology plays a pivotal role in technological development, cultural heritage, and social progress. In a field, there must be a unified, precise, concise, and unambiguous definition and scope, to avoid unclear concepts, unclear expressions, and puzzling. The accuracy and uniformity of the definition of terms will directly affect the promotion and application of the products, and the non-standard and inaccurate terminology will also cause great trouble to the work. Comparing and analyzing the standards in the field of surveying and mapping, it can be found that the definition or classification of some terms is not uniform.

The chaos of scientific terminology is caused by the unification of disciplines, industries, and individual experts. Breaking the boundaries of disciplines, industries, and individuals, and carrying out terminology norms and unification work in accordance with unified principles and methods, the meaning can be compared with the " unified transport system, single written language and same moral/ethical standards."

Geospatial information resources are important strategic resources. Fully developing and utilizing geospatial information resources is one of the important tasks of national informatization. The government's professional departments and relevant units have collected a large number of thematic geospatial data according to the needs of the work, and some have also developed and constructed thematic geographic information system. However, for a long time, various professional departments have different definitions of geographical elements and different classification standards,

*Corresponding author 
resulting in large differences in geospatial data produced by various fields, and the data standards are not uniform or even conflicting, and the use and sharing of geospatial data The huge impact has seriously restricted the process of information construction and caused a lot of waste of funds and information resources

Under the premise of the unified system and responsibilities of the natural resources department, natural resource management and various spatial planning do not need a comprehensive, unified and authoritative geospatial data as the basis for support. To realize the sharing of geospatial data, to solve the problem of counting multiple problems, it is necessary to formulate a scientific and unified definition, classification and code system of geographic elements.

\section{RESEARCH CONTENT}

\subsection{Standard GB/T 20257}

The GB/T 20257 series of standards is divided into 4 volumes. The definition, classification and symbol design of the geographical elements involved in the 1:500-1:1,000,000 basic scale topographic map are the basis and norms for the measurement and compilation of topographic maps. Its predecessors are standards GB7929, GB5791, GB15944, GB14512 versions. In order to adapt to the needs of economic and social development and changes in the expression of geographical elements, the intermediate has undergone several revisions to increase, supplement or improve some of the geographic information elements. The 2017 version was approved by the National Standardization Administration Committee in 2013 and was released on October 14, 2017. It will be implemented on May 1, 2018.

This paper takes the geographical factors such as water system, residential area and traffic in the GB/T 20257 series as the object, and uses the methods of literature review, research and expert consultation to compare the definitions of these geographical elements in the departments of water conservancy and transportation. Geographical elements that are unscientific, inaccurate, non-standard, and ambiguous are defined in the GB/T 20257 series of standards.

\subsection{Water system}

2.2.1 Lakes and ponds: In standard GB/T 20257, the lake is a water body formed by the accumulation of water on the land, which has a wide water area and a slow change in water quantity. The pond is a manually excavated stagnant water body or a naturally formed small-scale hydrothermal water body.

In standard "China Lake Name Code", the lake basin and its accepted water body (including intergranular brine) are called lakes. The lake basin of the lake is a relatively closed natural depression on the surface. Hydrological Basic Terminology and Symbol Standards: Water storage on land. A complex natural body of broad waters consisting of lake basins, lake water and the materials contained therein. Usually the ponds are filled with no ground. They rely on natural groundwater sources and rainwater or artificially divert water into the pool.

If the definition of pond is only the "water excavation" of the water, the distinction between "lake" and "pond" is not controversial, but the definition of "pond" is also "or the natural formation of smaller depressions". There are two problems in the content of the water body: One is the pond artificial or natural, another one is how large is the area "small area"?

2.2.2 Bridge and culvert: GB/T 20257 definition of culvert: Construction of water or passages under structures such as roads and dams. But in standard "Glossary terminology for highway engineering": A small-sized drainage structure that is mainly used for venting surface water flow and crossing an embankment. It is generally composed of a foundation, a hole, and a hole. Where the single hole span is less than $5 \mathrm{~m}$ or the total length of the porous span is less than $8 \mathrm{~m}$, it is called culvert. Pipe culverts and box culverts are called culverts regardless of the span.

2.2.3 Swamp and wetland: GB/T 20257 definition of swamp and wetlands: areas where the ground is wet for a long time, muddy or flooded (including seasonal wet grass). In standard "Glossary of Geography": A geologic complex of aquatic organisms and aquatic soils developed in moist or shallow waters. These include natural and artificial, permanent and temporary types of swamps, peatlands, salty and freshwater bodies on land, and waters within 6 meters of water at low tide levels. In standard "Glossary of Forestry": natural or artificial, permanent or temporary stagnant or flowing water, fresh water, brackish or salt water marshes, peatlands or waters. Includes waters with a water depth of no more than $6 \mathrm{~m}$ at low tide. In 
standard "Basic terminology and symbolic standards for hydrology": swamps, soils are often saturated with water, long-term or temporary accumulation of water on the surface, growth of wet and marsh plants, accumulation of peat or areas where there is no accumulation of peat but burial layers.

2.2.4 Island: In standard GB/T 20257, island is a sea or river, a lake, a reservoir surrounded by water and a land that rises above the water year round. In the rivers and lakes, the boundary between the water body and the land is basically fixed because the water level does not change much. However, due to the effect of the tide, the sea level changes greatly, resulting in the boundary between the sea body and the land. Changes are also not fixed, which leads to many differences in the identification of islands at sea.

The explain of island in the Modern Chinese Dictionary (5th edition) is " The land surrounded by water in the ocean and smaller than the mainland. It also refers to the land surrounded by water in the lake and river. " If it is only perceptual If you know the island, such a definition is still true. However, when you accurately distinguish the concepts of islands and reefs from the concepts of the " islands " and " reefs " in law, such definitions cannot meet the requirements. In GB/T18190-2000 " Ocean terminology marine geology ", an island refers to a small piece of land scattered in the ocean with an area of not less than 500 square meters. However, the legal definition of the island has always been controversial internationally and has been revised many times. It is now usually stipulated in Article 121 of the 1982 United Nations Convention on the Law of the Sea: " The island is surrounded by water and is higher than it is at high tide. The naturally formed land area of the water surface."

The definition in the United Nations Convention on the Law of the Sea is very effective in defining the isolated islands in the ocean. However, there is a problem in defining whether the protruding land around a large island is an " island ": what is surrounded by water? Time is surrounded by water? Is it surrounded by water on the climax, or is it surrounded by water at low tide, or is it surrounded by water for most of the day? In fact, this issue involves the question of how the boundary between the island and the sea is defined. This problem is not solved well. A series of problems on the island's area and coastline will not be solved perfectly (XU Hui, MAO Lamei, AI Min, 2012).

\section{3 residential area}

2.3.1 Urban and rural division: In the surveying and mapping work, it is inevitable to encounter a series of problems such as " the size of the urban area ", " the edge of the city " or " the boundary between urban and rural areas ". The dividing line between urban and rural areas refers to the dividing line between urban areas and rural areas. In ancient times, there were walls around the city, and the walls could serve as a clear boundary between urban and rural areas. Modern cities and towns are generally developing towards urbanization. When the population gradually gathers and the urban areas expand to the original rural areas, the urban-rural boundary line becomes increasingly blurred. Therefore, it is not simply based on the definition of a town administrative district that the actual towns and villages can be strictly distinguished. To correctly answer these questions, it is necessary to define the definition and classification criteria for cities and villages.

Urban and Rural Areas Implementation Measures: Towns include urban areas and townships. The urban area refers to the residents committees and other areas connected to the actual construction of the municipal and district-level cities, districts and municipal government residences. The township refers to the resident committees and other areas of the county people's government residences and other towns outside the urban area, the actual construction of the government station. It is not connected with the actual construction of the government resident, and the resident industrial and mining areas, development zones, scientific research units, colleges and universities and other special areas with permanent populations of more than 3,000 people and the farms and forest farms are regarded as towns. The village refers to the area outside the town defined by this regulation.

2.3.2 Block and street: GB/T 20257 uses the street to define the block, and at the same time uses the block to define the street. This is more or less a "circular argument" shadow. Because there is no accurate and strict definition, there is no unique position on the sidelines of the street and the sideline of the block. Different operators and different inspectors have different understandings. In the same picture, different people, the representation of streets and neighborhoods will be very different.

Standard " Glossary of Architectural " defines a block: an area defined by a natural boundary ( such as a river ) or a street in a town. In the urban area, various building are built on both sides 
of the whole road or most of the sections, and roads with sidewalks and various municipal utilities are provided.

\subsubsection{High-rise building and super high-rise building: GB/T}

20257 defines 10 to 18 floors building as high-rise building, and 19 or more floors are super high-rise building.

In standard " Code for Fire Protection of Building Design ": High-rise building are non-single-storey building, warehouse and other civil building with a building height of more than $27 \mathrm{~m}$ and a building height of more than $24 \mathrm{~m}$. In standard " Technical Regulations for Concrete Structures of Tall Building ": Ten-storey and ten-storey residential building with a height of more than $28 \mathrm{~m}$ and other high-rise civil building with a height of more than $24 \mathrm{~m}$ are high-rise building. In the United States, $24.6 \mathrm{~m}$ ( 80 feet) or more are considered high-rise building; in Japan, $31 \mathrm{~m}$ or 8 th floors are considered high-rise building; in the UK, building equal to or greater than $24.3 \mathrm{~m}$ are considered high-rise building.

In mainland of China, building codes stipulate that super high-rise building are more than 100 meters high; Japan and France define super-high-rise building over 60 meters; in the United States, building above 152 meters (500 feet) are generally considered skyscrapers. However, according to the current new standards of the World High-Level Architecture Society, more than 300 meters can be classified as super high-rise building.

\subsection{Traffic}

2.4.1 City Road: GB/T 20257 divides city road into main road, secondary trunk road and branch line. The main road is a channel with a wide road surface and a large traffic flow in the urban road network. The secondary trunk road is a regional trunk road in the urban road network. The traffic flow is large and connected with the main road to form a complete urban trunk road system. The branch line is the street, lane of the main and secondary roads in the town or used for the interior of the area.

In standard " Code for Urban Road Traffic Planning and Design

": The main road should be the trunk road connecting the main sections of the city, with traffic functions as the main. When the amount of bicycle traffic is large, it is advisable to use a form of separation between motor vehicles and non-motor vehicles, such as three roads or four roads. Import and export of public building that attract a large number of traffic and people flow should not be provided on both sides of the main road. The secondary road is an auxiliary traffic route between the main roads. The secondary trunk road is the city's traffic trunk road, with regional traffic functions as the main function and service functions. It forms a road network with the main road, which connects the various districts of the city and the main roads. The feeder line is the road that is connected to the secondary trunk road outside the trunk road in the urban road network or used inside the region.

2.4.2 Rural road: GB/T 20257 divides rural road into machine-farming road and country road. The machine-grown road is a road that has been simply paved, but has no roadbed. It can generally pass through tractors, carts, etc. In some areas, it can also pass through cars. It is a channel for agricultural machinery (tractors, harvesters, etc.) to enter and leave the field for farmland operation. . The country road is a road that cannot pass big cars or tractors.

At present, the hardened roads in rural areas of China have already reached a considerable scale, basically forming a network of rural hardened roads connecting thousands of households. For surveying and mapping workers, the identification and classification of these hardened roads is a realistic problem ( LIU Nian, YANG Xinhai, XI Hongru, 2012 ). For the sake of simplicity and convenience, many surveying and mapping workers classify the hardened roads in rural areas into " machinery roads ", and some people classify hardened roads in rural areas into " roads ". The two manifestations have their own reasons, and they have been arguing for several years. For the designers of surveying and mapping products, in the absence of relevant surveying and mapping standards, some of the professional design books are classified as " highways ", and some are classified as " machinery roads "; The quality inspection department of the product is also difficult to master and can only be implemented in accordance with the provisions of the professional design book.

\section{CONCLUSIONS}

The GB/T 20257 series of standards and related standards have different definitions of the same geographical elements, they also create some glossary of geographical element which do not appear in the standards of the competent authorities, such as the disappearing river section, high grassland, and more The 
classification of geographic elements into one class is not conducive to fine management, such as the combination of swamp and wetland. The latest revision has incomplete geographic elements, such as charging piles, country roads, UHV/UHV transmission lines, and wide-track railways.

The research work and result are conducive to guiding the quality inspectors to change their concepts, change the concept of the surveying and mapping unit based on me, and establish the basic concept of correctly treating the discourse power of the competent unit and the surveying and mapping unit in the cross-disciplinary field.

\section{ACKNOWLEDGEMENTS}

Founded by National Natural Science Foundation of China (416 $71440)$.

Founded by the Quality Wing Program of National Quality Inspection and Testing Center for Surveying and Mapping Products (2018).

\section{REFERENCES}

XU Hui, MAO Lamei, AI Min, 2012: The Necessity to Develop

an Standard Definition and Classification System for Geographic Elements, Geomatics Technology and Equipment, Vol.14, No.4, 54-56.

LIU Nian, YANG Xinhai, XI Hongru, 2012: Representation based on rural hardened roads in DLG and cartographic data, Geomatics Technology and Equipment, Vol 14, No.3, 23-26. 